\title{
Lilac Tree and Edam in Berthe Morisot's 1874 Plein Air Paintings: The Feminine Figure and Its Expressions
}

\author{
Zuyan Zhang ${ }^{* 1}$ \\ ${ }^{1}$ Barstow School on Ningbo Campus, Ningbo City, Zhejiang Province, China \\ ${ }^{*}$ Corresponding author. Email: zhangzuyan@hanvos-kent.com
}

\begin{abstract}
The exploration of Hunting Butterflies reveals the formation of artistic awareness of Morisot and the value judgment of modern females. Similar debatable perspectives (e.g., feminism, modernity, and maternity) have been remarkable focusing for art historians, feminists as well as Marxists. Women's power is dissolved with Morisot's blessing in Hunting Butterflies by concerning Morisot's complex relationship with Edma and comparing Beneath the Lilacs at Maurecourt. Morisot's purpose is uncovered by Growing patterns, shadows and lights, relationship with figures of the identical lilac trees in two painting as well as figurative interactions. The contrast of clothing colors, remote distance from lilac tree, and isolated interaction with children create a modern female figure in Hunting Butterflies. Morisot blesses Edma in the painting with the values of independent females based on the support from family, and reconciles with Edma after their fathers' death. Hunting Butterflies not only contains the mourning of Morisot's father, but also represents warm female power, living vitality, pursuit of freedom dissolving in a modern feminine figure.
\end{abstract}

Keywords: Feminine figure, Morisot, Edma.

\section{INTRODUCTION}

Impressionism originates as a rebellious school of art challenging conventional artistic perspective and social expectation. Impressionists build ideological system and convey works' impression to viewers. Art historians reckons gendered identity of impressionism, which dissolves depicting techniques of male artists but mingles elegance and softness by females' perspective. Female impressionists are either strong-hearted to betray social expectation of stereotypical housekeeper. In late nineteen centuries, citizens derived the demand for individual pursuit of modernity. Artists explored modern pursuit for self-identification, laborious/ideological means, and even regards them as Marxism with hierarchical systems [1]. Impressionists dismantle domestic labours while endow women with new living patters and female powers. Except of impressionistic ideology, artistic techniques are preeminent. The mechanism of capturing momentary is pervasive among impressionists. Artists encourages each other to paint outside of studios, i.e., natural scenes are crucial motif of the paintings. The terminology momentariness, following the guidance of Pierre-Henri, dominates artists' canvass [2] forming the illusive values of impressionism [3]. The ephemerality and sensitivity, which is the intrinsic of impressionism, contain feminism. The confinement of space and time emancipates limits of shapes and state of forms. The noticeable brushstrokes and obscure depiction of forms occupy majority of impressionist arts. Therefore, the orientation of arts inclines free and self-expression. These qualities and conflicts narrow the protagonist to Berthe Morisot.

Accordingly, feminism, modernity, momentariness and painting techniques are the major concerns when scholars explore Morisot [4]. All these four aspects connect with her sister Edam, who also became one of her models. Tracing to the origination of creating art works, domestic sphere haunted Morisot with the central relationship with her sister. Morisot's art expressions were based on her loss and desire relation with Edma's marriage and their rupture [5]. The figure of modern females portrayed by Morisot were shaped by her sentiment of Edma. Morisot translated her experience into art as well as redefined female identities and women's power under her brush.

The selection of Hunting butterflies extracts historical female characters in Impressionism. It creates self- 
identification and shapes modernity of female figureEdma. Hunting Butterflies associates with Beneath the Lilacs at Maurecourt were painted by Morisot in the same year. They share the same element of the identical lilac tree, wearing patterns, lights, and familial interactions. The comparison between the two paintings compellingly demonstrates the women's power and feminism in Hunting Butterflies. Traditionally, scholars separate Morisot's career into two sections and endows them with qualities of domesticity and modernity in Birthing in Modernity. The means of modernity and struggle of female individuality are melting in maternity among Morisot's creation [6]. Hunting Butterflies corresponds with shaping modern female figures and ensures the independence of women. Moreover, it constructs colours, suggestions, and open brushstrokes in feminine arts contending by garb. These techniques betray traditional male's provision of impressionism in a more rational perspective. The sensitive and impressionistic canvas provides an ephemeral platform shaping female protagonist [7]. Hunting Butterflies upholds gender as social determined factor, and denies male gaze since it forms a modern female.

\section{INTERFLOW SPACE}

The composition on of the canvas represents that the woman is as the central figure in of the scene. The painting is in oiled media and in executed En plein air (painting outdoor) [8]. The protagonist (the woman) is illustrated in a large portion on the canvas, which is placed inclined prone to the right in the middle and more prior to the audience than her children. The woman in the specific placement is more amiable toward viewers. The large green tree sits parallel with the woman in the space and occupies the canvas diagonally left for one quarter. The lilac tree is positioned diagonally right about $2 / 3$ area. The distance between the woman and lilac tree leaves recession for constructing space. The green leaves and lilac flowers extend to the upper frame while grasses stretch among the low frame. In addition, the foreground and background positions of the two trees are connected by the mixture of leaves and flowers, which creates a uniform environment to envelop the woman and her children.

Focused on human forms, the figures are fragmented in the scene and sectioned in two parts. Three children form a close cluster on the left side, but the woman is sole character on the right of the green tree creating a physical distance. The woman as the mother is separated from her children by the diagonal line of the butterfly net parallel to central diagonal in scenery space. Moreover, the gesturing pattern are distinct. In detail, the two children in white bent their body toward the ground with inward pattern while the white-dress girl and the woman are standing. The group opposite gestures are symmetrical. Once being looked closer, the clothing pattern of standing figures are opposite. The woman wears white gown with black hat and black scarf with rose patterns, but the girl dresses in black with white hats. Besides, the woman holds butterfly net and bents her left elbow higher than her right arm. Whereas, the girl loosens her left arm and bents her right elbow at higher position. Their body treatment forms mirror effects in the scene as two vertical forms. In contrast, the family in Beneath the Lilacs at Maurecourt displaces entirely different gestures. The family are clustered together in sitting. Their garment are opposite colours with them in Hunting Butterflies. The mother in Beneath the Lilacs at Maurecourt wears in black with white hat and scarf, and her children attire in bright colours. Comparing to apparent rejected eye contact of the family in Hunting Butterflies, the woman owns forthright eye contact and legible complexion. Nevertheless, her children's faces are obscured without facial expression.

\section{THE LILAC TREE}

Morisot associated the external environment with the female figures under her brushstroke. The use of colour, still life, light, and facture, indicate the central role of the woman in the Hunting Butterflies. In the background, vast green woods accompany with the lilac tree on the right. Aggressive green occupies the space, but the lilac tree supports the back space and connects with the forward position. The lilac tree and the green tree forward form a link to construct the entire space. The lilac tree positions major in the upper right area of the intersection of two diagonals on the canvas. The trunk of tree inclines to the left side on the canvas with large angles, where its branches extend the half of the upper frame in the painting. In the scenery space, the lilac tree separates with the woman as recession on the background. As the supportive still life, lilac tree mingles with the green tree because of its floating and piecemeal flowers (located in the air and on the green leaves).

The lilac tree's position is opened upward and to all around in flourishing pattern. The lilac flowers are fragmental and shapes in integral. It dots on the branches but not crowed. Morisot utilized careful treatment on lilac flowers instead of open brushstroke treating on its surrounding green leaves for their lush growing pattern. Moreover, the different shapes of lilac flowers convey various meaning. To be more specific, the lilac flowers are somehow integrally mature, or grow as young buds. On the bottom of the lilac tree, the brown color expands to the green grass and melts together like flows, which is the age of bloom and roam wild. The pink color of the flowers is tender and pure especially reflecting by the cool and profound green background. Besides, the pink color is also varied, e.g., denser and bright crowed in the area of flowers, translucent due to covering by the color of leaves. Moreover, the pink color depicts the trunk of the lilac tree and renders the brown trunk with soft form. 
The sparseness of lilac flowers is determinant of pattern of lights. The concentration of lilac flowers is more approachable to viewers, which leaves a relatively empty space in the background. The empty area between the flower branches and the back leaves exposes blue sky. The blue sky brings more lights to the scenes and emphasizes the lightness in the paintings. It reveals that the light directions are parallel to the diagonal originating from the upright. The lightness on the lilac flower is bright and glimmering. The outstanding light is glint like the light on the woman's dress. The relucent lights differentiate from the dark green plants on the back. Compared to Beneath the Lilacs at Maurecourt, where its lilac leaves cover the dark sky area. Thick and lush lilac leaves create the dark shadow on the ground. The only bright substances are those clothe elements including the white hat, scarf of the woman, children's dresses, and the basket.

The lilac tree in Beneath the Lilacs at Maurecourt (Morisot another painting), acts in a more supportive role than in Hunting Butterflies. The lilac tree originates from its roots paralleled left to the intersection of the diagonals. The composition of the lilac tree places the major parts of the upper area sectioned by diagonals. It occupies more space than in the Hunting Butterflies and contains the upper frame with larger width. Instead of merely supporting space, the lilac tree functions a canopy above the family. It grows inclined to the right side of the canvas forming a symmetrical impression. The shape of lilac tree seems an inverted triangle as a stable form. The figures in the painting also incline to the lilac tree as the origin. In comparison, the color of the lilac tree is darker on its trunk and flower. The outline of the tree is emphatic, and the use of trunk indicates its heaviness and denseness. The brightness of the white flowers is losing while flowers are obscured by its surrounding leaves. The facture of the flowers is loose and quick, which shapes the pattern and outline of the flowers in lush leaves. Meanwhile, there are blooming flowers on the trees but merely intersperse in the leaves in Hunting Butterflies. Besides, the natural settings are opposite, where the lilac tree leaves a light area on the ground but surrounding by dark green plants in Hunting Butterflies. The bright shadow is another lightening element except the highlighted dress of the woman. However, the lilac tree produces a dark shadow on Beneath the Lilacs at Maurecourt. The canopy-shape shadow on the bottom connects with the canopy of lilac tree on the top which entirely envelops the family. The around space is lightened by the bright basket or the light ground on the background.

\section{MOMENTARINESS}

Historians contend that impressionists are more willing to capture instant scenes than academic artists [9]. The values of instancy and uncertainty achieve peculiar effects of flow and movement in impressionistic paintings. Morisot dares to immediately capture natural scenes outdoor instead of in studios for the second creation. The value of momentariness exists in the corners of her painting.

Colours are flowing in the space, in which momentary effects emphasize contemporary states of natural forms. Green pigments overwhelm the canvas where the green of grass, leaves, and woods mingle together. The green is like the flow, the green of grass from the ground could dissolve with the green of leaves. There is no boundary between the leaves background and the tree which covers the hind boy. The green interconnects with background forward, upper as well as bottom space, i.e., the space roving in every second. The overwhelming green color creates uniformity, which either created by the brown from the roots of the upright tree or extended and melted with the surrounding greens. The green exists from the top to the bottom of the painting framing the importance of woman in the canvas. The unlimited green extends to the frame that creates an ambiance to place viewers into the same scene with the woman. Whereas, the dissolved greens are distinguishable with each other. The grassland green grass is distinct from the light green of scrub or the flourishing dark green leaves. The shadow area of the lilac tree is brighter than the extensive leaves and grass. However, the melted green curtails the effects of recessionary depth of the painting, since the canvas is flat and shallow. The tone in the scene is cold because the extensive green and purely white. Nevertheless, the warmth is shining from the shimmering lights spread on the canvas, which lighten the grass, dresses, and flowers. The lightening portion is changing along with the drawing sight and time, i.e., lights are either instantaneously changeable.

Not only color uses capture the changeable environment, but also the facture could indicate the states of forms. Impressionists rebel the traditional brushstroke of academic artists and dare to use more open facture on the painting. Art historians have concerned on the prints of Cassatt and Morisot. Cassatt uses tenser and detailed brush treatment to forms while Morisot utilizes freer and loose facture to shape instead of interior depiction of forms. Morisot's outstanding facture is distinguishable and rebellious.

However, her brushing trait rather creates vitality and momentariness on paintings. Back to Hunting Butterflies, the rapid brushstrokes melting natural forms together with the leaves on the top of the frame and the grass on the bottom. The space is associating and flowing as momentary. The facture of grass is short and vertical, which indicates the upward growing pattern of grass. The radical and clustered brushstroke reveal pervasive and lush leaves. The dotted and quick facture of flowers stresses indicate flowers interspersed on the branches and their falling states temporarily. The natural forms are 
delicate and readily variable. They are seemed to be blew by breezed and presented their different inclination in the environment. The loose facture also implies the sketch of drawing pattern on the canvas. The factures of garments of the woman and children demonstrate the momentariness of chasing butterflies in the scene. The soft brushstroke of the woman's garment indicates its lithe comfort. The long brushstrokes of the dress, the semi-translucent fan, and the round hat refer the woman's identity is upper-class. Her leisure could be implied by her causal and lightsome clothes. The lithe and loose garment is varied in next moment due to the shaping varying of the soft cloth. The black rose pattern on the woman's fan corresponds to the naturally outdoor environment. Morisot employs greater resolution in the woman's depiction by portraying in "unfinished" method for surrounding.

The floating elements echo with each other for their variability. On the top frame, the flapping element refers to lilac flowers. Lilac flowers drift along with breeze from lilac tree. The flowers on the tree are swinging like falling down on the ground. On the bottom frame, the flying substances are butterflies which move among grasses while sometimes hide behind the grass (undetermined). Even though flowers are natural forms and butterflies are animals, they share similarities. The flowers own the similar shape of butterflies which have four parts of a pair of wings. Butterflies are not identifiable flying into grass, but their glimmering and swinging movements could determine their position instead of solid appearance like lilac flowers. Moreover, the flying state of butterflies and flowers is momentary. Their flying movements produce the visual effects of glimmering while they are flickering. When flowers fall on the ground, it could not identify light dots, flowers, and butterflies since they are illuminated as white dots.

\section{SUBORDINATED LANDSCAPE}

Historians have reckoned that Morisot planed her canvas based on the figurative arrangement and producsd an open broad for natural settings. Disparate from Cassatt's technique that choosing open-air background to portray figures, Morisot depicted environment embracing characters with natural forces impressing viewers. The aim of natural scenes is to emphasize figures in paintings and visual effects. As a consequence, the figures are more vital with more characteristics by natural effects. Natural effects hint viewers for Morisot's purpose and meaning.

In Hunting Butterflies, landscape completely serves for figures and emphasizes the central role for the woman. The woman's position is the most frontal to viewers in the scene, which provides more chances for viewers to sense the woman when they confront to the painting. Both her occupied space and middle place indicate the central role in paintings. Her figure is larger than other, and the isolated space in the scene determines her importance on the canvas. The title is "Hunting Butterflies", and the woman is the only figure who holds the butterfly net slantly. The action echoes to the theme of the painting indeed indicating that the woman is the center. Moreover, the color usage demonstrates a shiny woman. The overwhelming green fills major parts on the painting and even creates calm ambiance for viewers. The extended green to frames creates an illusion to embrace viewers into the same setting to interact with the frontal figure. The ubiquitous green has considerably reflective force to the white color of woman's dress. Her dress impressively concentrates gazes from viewers. The natural lights seem to glint the white color and indicates its brightness especially when the woman in white positioned in the dark green scene. The green color is dynamic owing to the ligation between upper and bottom space in the scene. The dynamic green always encircles the woman and makes her as the center in the green circle. Not only capturing the gazes from viewers, the woman is also focused by her child as well. One of her children wears in white stands to watch her mother chasing butterflies. Although her face is obscures, her eyes' sight orients to the woman. Gathering nature's concern and daughter's stare, the woman is controlling the entire space.

Morisot utilizes Manet's modulation of black color for particular purpose [10]. The flatness of black involves specific treatment for figures and landscape. The lightness and darkness are noticeably opposite sections of Hunting Butterflies and Beneath the Lilacs at Maurecourt. Lilac tree is the identical element in these two paintings serving as strong indicator of the effects of lightness and darkness. Lilac tree in Hunting Butterflies produces a light shadow on the ground and exposes bright sky for the natural scene. The color of lilac tree is glimmering that glints the right portion of the painting. The shiny effects match well with the white dress of the woman in the scene. The light scene produces a broad and profound visual effectiveness for viewers. In contrast, Beneath the Lilacs at Maurecourt is embraced in a serious tone. The lush leaves of lilac tree and interleaved lilac flowers occupy the upper frame, which fills air interval in paintings as well as suffocates viewers when they confront to this painting. The frondent lilac tree produces dark and dense shadow on the ground as a canopy to envelop the family under the tree. This shadow extends to the frame until the existence of the white baskets on the lower right side. The shadow on the ground is in the shape of lilac leaves. The mirror effects of canopy settle the canvas with heavy senses. The darkest site on the canvas is rather the woman's dress which is flatly dark. The flat dark is calm and immobile while other dark sites like shadow seem to originate from the black dress of the woman. Beneath the Lilacs at Maurecourt is created in 1874 before the creation of Hunting Butterflies, which is the same year when Morisot's father passed away. Edma wearing in black in Beneath the Lilacs at Maurecourt 
indicates that the sisters are experiencing the pain of losing their father on account of the mournfulness and grief meaning for the color. Adding the same meaning of lilac tree, it is reasonable that Beneath the Lilacs at Maurecourt has a heavy tone. Backing to Hunting Butterflies, even though Edma is in white, sisters' sorrow is also indicated. Wearing in whites alludes that there is a period after Morisot's father's death. The black color of the woman's hat in Hunting Butterflies contrasts to the white hat in Beneath the Lilacs at Maurecourt. Besides, the black scarf with rose pattern dot the mournfulness for Morisot's father. However, the lush lilac flowers add more brightness and luminosity in the scene. The white dress with the glint scene shows the comforting sense after father's death. The different light and shade imply the mental state of Morisot.

\section{WOMEN'S POWER}

Historians traditionally believe that the existence of lilac tree in Hunting Butterflies and Beneath the Lilacs at Maurecourt mainly shows the grief of the two sisters. "Berthe has constructed an image designed to satisfy her own needs" [11]. The portrayal of Edma is the mirror of Morisot herself. She uses Edma as the sentimental conveyancer to express her sorrow and miss to her father. She not only uses Edma's figure, but also alludes the meaning by depiction of the lilac tree. Lilac flowers contain mourn senses and the innocence which shown in the drawing of Edma's children. However, one can contends that Morisot want to express woman's power after her father's death instead of demonstrating a delicate female figure in Hunting Butterflies.

The black dress color in Beneath the Lilacs at Maurecourt is transitioning to white in Hunting Butterflies. The black represents to the time of mournfulness of Edma and Morisot's father and indicates the role of mother and mourners for Edma and tense relationship between her and Morisot. However, the white color is comforting, which defines past time for their father and the innocence of woman under the scope of father. It ties with the miss and affection from Morisot toward her father. Edma is the embodiment of Morisot, i.e., her figure entrusts profound sentiment for their father. Moreover, white indicates the reconciliation of the two sisters. Morisot has considered that Edma is transgressive when she got married. Morisot initially could not understand Edma's decision to be family-oriented. Their strained relationship is comforted and the rupture is bridged when their father passed away. Morisot seems to lay down her heart knots and repair their relationship.

The figurative treatment on Edma indicates the warmth of females. Comparing to the facture of forms, Edma's complexion in Hunting Butterflies is extensively apparent and clear. In Beneath the Lilacs at Maurecourt, Edma lowers her head without direct contact to the viewers. Children's facial expression are obscure both in
Hunting Butterflies and Beneath the Lilacs at Maurecourt. The hazy children's faces indirectly indicate that women are central figures. Backing to Hunting Butterflies, Edma's eye is forthright to viewers. Specifically, she is brave to face directly to strangers by her persistence and courage instead of escaping eye contact like in Beneath the Lilacs at Maurecourt. Her complexion is fond and elegant that echoes with her upper-class identity and the warmth of female characteristics. Lilac flowers have the vitality and bravery meaning, i.e., the more luxuriant lilac flowers in Hunting Butterflies imply the more energy containing by Edma also Morisot. It connects to the background of father's death of Morisot. The vitality which the woman expresses is the new optimistic attitude after losing father and the power when modern females experience earthshaking changes in their lives.

Women's power originates from family but exceeds to females themselves. In Beneath the Lilacs at Maurecourt, figures share more interaction than in Hunting Butterflies. Edma's children lean to her. Whereas, Edma presents an inward gesture which indicates that she does not want to embrace outside environment. In contrast, Edma in Hunting Butterflies breaks through conventional female figures in that era. She keeps the physical distance from her children and forms an isolated zone in the space. Children's stare is following Edma's movement of chasing butterflies rather than being a mother to care their children traditionally. Besides, in Hunting Butterflies and Beneath the Lilacs at Maurecourt, Edma's gesture demonstrates her attitudes toward her own lives. In Beneath the Lilacs at Maurecourt, Edma sits on the ground and her dress extends until dissolves with the dark portion of shadow. She surrenders to her pasture and familial boundary. Nevertheless, Edma confirmedly stands on the grass denoting the no longer yielded attitude. She has force to rebel to unfair lives and treatment due to her gender and identities. She is persistent to sight directly and unbending to stand for the sake of exhibiting the persistent and self-affirmation woman's power. Edma bents her left elbow and her standing girl bents her right elbow. The mirror effect is demonstrated based on their contrast clothing colors. It alludes that even though the physical distance isolates Edma from her children, their bloody lineage still exists and connects with each other. However, Morisot deliberately positions Edma frontally and treats her figure considerably larger than her children. It breaks the confinement of Edma's family and indicates that Edma's individual ideology will exceed the restraint of domestic sphere. In addition, Edma is restrained by the cage of family, like the butterflies, according to the meaning of hunting butterflies. However, she is holding the butterflies denoting that she is able to support and hold her own family. It is the progress of woman's identity in society. 


\section{CONCLUSION}

In summary, Morisot's art pursuit continually involved her exploration about modernity of females with maternity. The figure of Edma in Hunting Butterflies is Morisot's reflection of the genuine embodiment of modernity. It is not perfect melting Morisot's exploration yet, since the modernity is not absolutely independent and casting off family from her perspective. Edma in Hunting Butterflies is bond to family but presents a new attitude toward her life.

Instead of shaping an ideally modern female figure, Morisot dissolves her blessing to Edma, which is not typically aggressive with the wish to get rid of family. In other words, the fondness and elegance of the woman determine the tone of the painting. Detailed lilac flowers and sight perspective contain Morisot's expectation that concentrates on Edma. Morisot wanted Edma to transfer her attention (e.g., own hobbies or loves) from family more to herself. This is because the moral of Hunting Butterflies is for chasing happiness instead of truly pursuing to capture Butterflies. Morisot expects Edma to recollect and restart painting like they were young and does not want familial life will dim Edma herself. Moreover, the sight perspective desires fairness for entire modern women. Initially, impressionists paint women in the scope of males which is erotic. The shadow is the indicator of the transferring sights in Hunting Butterflies and Beneath the Lilacs at Maurecourt. In Beneath the Lilacs at Maurecourt, the shadow is tense, which indicates that viewers are overlooking the painting. It associates with the underestimated sight from males toward women in society. Nevertheless, in Hunting Butterflies, Morisot ignores males' gazes and deliberately lowers the sight and forms a horizontal viewing point. Thus, women have chance to sight directly and will own fair opportunities like males. It could not immediately achieve but as the wish to encourage females.

\section{REFERENCES}

[1] Therese Dolan, "Perspectives on Morisot." Woman's Art Journal, Vol. 15, No. 2 (Autumn, 1994 - Winter, 1995), pp. 40-43.

[2] Pierre-Henri de Valenciennes, "Reflections and Advice to a Student on Painting." Particularly on Landscape, 1800.

[3] Joshua Taylor, "Nineteenth Century Theories of Art", University of California Press, USA. 1989, pp. 246247

[4] Bernard Denvir, "The Thames and Hudson Encyclopaedia of Impressionism" London: Thames and Hudson, 1900.

[5] Marni Reva Kessler, "Reconstructing Relationships: Berthe Morisot's Edma Series." Woman's Art Journal 12, no. 1 1991, pp. 24-28.

[6] Schuyler Krogh, "Birthing the Modern: modernity, maternity, and subjectivity in the art of Berthe Morisot.", University of British Columbia, 2015, p iv.

[7] Christine Havice. "The Artist in Her Own Words." Woman's Art Journal 2, no. 2 1981, pp. 1-7.

[8] Francis E. Hyslop, Jr. Berthe Morisot and Mary Cassatt, "Berthe Morisot and Mary Cassatt." College Art Journal, Vol. 13, No. 3 (Spring 1954): $178-184$

[9] Anne Higonnet, "Berthe Morisot." 1st ed. New York, N.Y: Harper \& Row, 1990.

[10] Anne Higonnet, "Berthe Morisot's Images of Women." Cambridge, Mass; London: Harvard University Press, 1992.

[11] Marni Reva Kessler, "Unmasking Manet's Morisot." The Art Bulletin 81, no. 3 September 1999, pp. 473489. 